\title{
Gobiernos seccionales en Ecuador: estatismo y estatalidad en crisis (1998-2009)
}

\author{
Gaitán Villavicencio L.*
}

\begin{abstract}
Resumen
En el contexto del boom democrático de los años ochenta, la mayoría de países latinoamericanos y del mundo vivió múltiples impactos; uno de los temas que adquirió protagonismo a raíz de esa ola reformista fue la modernización del Estado a través de la descentralización de los gobiernos seccionales, considerada una de las principales estrategias políticas para flexibilizar y democratizar los sistemas políticos institucionales centralizados y rígidos. Esto, en algunos países, favoreció el diseño de sus propios planes de desarrollo a los gobiernos locales. En otros, como en Ecuador, no tuvo mayor repercusión; fue más un discurso que una práctica política consolidada en las regiones geográficas, provincias y municipios.
\end{abstract}

\section{Palabras clave}

Territorio, gobiernos locales, Estado, descentralización, democracia.

\begin{abstract}
In the context of the democratic boom in the 80's, most of the Latin American countries and nations from other parts of the world lived multiple impacts; one of the topics that got prominence from that reformist movement was the modernization of the State through the decentralization of the sectional governments, considered as one of the main political centralized strategies to make flexible and democratize the centralized and rigid institutional political systems, this, in some countries, favored the design of their own developing plans for the local governments. In others, like in Ecuador, it did not have repercussion; it was more a speech than a consolidated political practice in the geographical regions, provinces and cities.
\end{abstract}

\section{Key words}

Territory, local governments, State, decentralization, democracy.

Forma sugerida de citar: Villavicencio, Gaitán. 2010. Gobiernos seccionales en Ecuador: estatismo y estatalidad en crisis (1998-2009). Universitas 13. Julio/ diciembre. Pp. 41-67.

\footnotetext{
Licenciado en Sociología Urbana y Diploma Especial de Posgrado en Desarrollo por la Universidad de Lovaina; Profesor de la Universidad Católica Santiago de Guayaquil y la Universidad de Especialidades Espíritu Santo; y Consultor/Investigador de la Corporación de Estudios Regionales-Guayaquil-CER-G.
} 
Tanto la derecha como la izquierda tienden a ser autoritarias cuando se trata de apoyar a gobiernos con los que simpatizan, pero invocan el respeto a las garantías democráticas cuando tratan de oponerse a fuerzas que pueden avasallar sus intereses. Si la democracia como régimen ha tenido una importante continuidad en los últimos años en nuestros países ha sido más por presiones externas que por fuerzas internas; consolidar la democracia requiere de élites más "maduras", por así decirlo.

Eduardo Dargent, Demócratas precarios. Elites y debilidad democrática en el Perú y América Latina

\section{Antecedentes}

En la crisis-transformación-construcción de la tríada Estado-nación-región/ local es muy significativo lo sucedido en el Ecuador, en el pasado lejano como en el reciente, en relación al desarrollo estatal-partidario y socioeconómico, con las propuestas y procesos para la implantación de la descentralización y/o autonomía en los gobiernos seccionales, vistas como un elemento imprescindible de una verdadera reforma y modernización del Estado y frente a la multidimensionalidad de los cambios exigidos por la globalización y la consecución del desarrollo humano.

En el contexto del 'boom democrático' de los años ochenta se produjo una ola de 'reformas estatales' con hondas repercusiones en la gobernabilidad democrática y en las prácticas de ejercicio del poder nacional y local. La mayoría de los países de la región latinoamericana y del mundo vivió múltiples impactos, entre los que destacó la incursión de nuevos actores políticos y sociales en la escena pública, la emergencia de marcos legislativos más flexibles para la toma de decisiones gubernamentales y el posicionamiento relativo de formas más plurales de concepción del poder político. Uno de los temas que adquirió protagonismo a raíz de esa ola reformista fue la modernización del Estado a través de la descentralización de los gobiernos seccionales, considerada desde entonces una de las principales estrategias políticas para flexibilizar y democratizar unos sistemas políticos institucionales relativamente centralizados y rígidos.

Desde el comienzo fue asumida por el imaginario político de gobiernos y organizaciones como una práctica redistributiva de recursos, competencias, 
espacios de decisión y responsabilidades, con diferentes grados de profundidad, modalidades, ritmos particulares y resultados según el país y los contextos locales analizados. En algunos países su implementación permitió mayor autonomía a los gobiernos locales, favoreciendo el diseño de sus propios planes de desarrollo. En otros, sin embargo, los programas de descentralización no tuvieron mayor repercusión pues, aunque formalmente se les otorgó más poder a las autoridades locales para resolver sus propios problemas, no se les proporcionó los instrumentos necesarios para llevar a cabo dichos proyectos, como en el caso de Ecuador.

En algunos escenarios, como ocurrió en este país, el fortalecimiento de los gobiernos locales a través de la descentralización fue más un discurso que una práctica política consolidada en las regiones geográficas, provincias y municipios. Las políticas descentralizadoras también fueron bloqueadas por las estructuras tradicionales de poder profundamente enraizadas en los sistemas sociales, que limitaron sus potenciales efectos.

Asimismo, el proceso de modernización del Estado tomó la forma de desconcentración administrativa, permitiendo que los gobiernos centrales delegaran algunas de sus funciones a los niveles más bajos de la pirámide administrativa-burocrática, bien dentro de los mismos organismos o ministerios gubernamentales, o desde fuera de la estructura burocrática central. Lo cierto es que, salvo en contados casos, es difícil asegurar que la modalidad asumida funcione actualmente de forma expedita en la transferencia de poder y autoridad. Incluso, es probable que nunca se haya realizado de forma radical y exitosa en la experiencia ecuatoriana.

Desde el restablecimiento del régimen democrático, en 1979, hasta la actualidad, la descentralización política y administrativa como estrategia de modernización en el país ha estado presente en el discurso de todos los gobiernos centrales y de la mayoría de los locales como un instrumento viable para la 'reestructuración' y 'democratización' del Estado. Sin embargo, luego de tres décadas, se observa con preocupación la existencia de más 'discurso descentralizador' que 'práctica descentralizadora'; es decir, la adopción, ejecución y concreción de estas políticas ha sido lenta y precaria, como lo destaca Verónica Silva en su tesis de maestría (UNAM, 2010, pp. 8 y 9). 
Inclusive, se debe resaltar que en los años recientes del nuevo milenio y siglo, como consecuencia del fracaso estruendoso de la "larga noche neoliberal", la pérdida de hegemonía de los Estados Unidos, la insurgencia de nuevas propuestas políticas de regímenes nacional-populistas basadas en un hiperpresidencialismo, la reciente crisis financiera global, entre otros factores, se ha producido un regreso fortalecido del Estado central, tanto en Latinoamérica como en Ecuador, que, basado en Constituciones Políticas 'garantistas', ha complejizado los procesos de reformas de los gobiernos seccionales que deben realizarse bajo el tutelaje del gobierno y la voluntad-discrecionalidad del presidente, provocando un estatismo desfasado, que no compagina con la realidad vigente y no profundiza la democracia, no construye ni más sociedad ni más ciudadanía, y la participación social es sólo un recurso retórico del poder, que construye una forma de estatalismo o estatalidad.

Finalmente, coincidimos con James Petras (Rebelión, 2001) —con el que lo hacen también autores como Ignacio Ramonet, Panajotis Kondylis, John SaxeFernández, Dan Schiller, Daniel Ilanes, entre otros-, cuando define al estatalismo como "un proceso de producción y reproducción del Estado bajo formas históricas, cambiantes, bajo una serie de resignificaciones. El estatalismo puede utilizar muchos instrumentos, pero los principales están dentro del propio Estado. Más aún, une, suelda, vincula, los instrumentos no estatales con los estatales. Toca y convierte en estatal lo que toca, como pasa con la publicidad estatal. La estatatalidad es el Estado en movimiento". Pensamos que esta aproche teórica nos va a permitir comprender mejor lo que está sucediendo en la actual coyuntura que vive Ecuador y la propuesta de revolución ciudadana en relación al regreso del Estado y los Gobiernos Autónomos Descentralizados (GAD).

\section{Fraccionamiento territorial y reacomodos de la representación política local}

Históricamente, de acuerdo a Jordi Borja (Repensando la Ciudad, 1988, p. 27):

El Estado moderno que se construye a partir de la Independencia adopta, casi podríamos decir inevitablemente, un modelo fuertemente centralizado. No solamente por razones económicas, administrativas e ideológicas 
de carácter general, como ocurre en Europa (creación de la infraestructura básica y de un esquema de administración pública, urgencia de cohesionar la nación embrionaria). También por razones específicas: poder político-militar que conquista el centro y debe construir el Estado-nación combatiendo tanto a los vecinos para consolidar las fronteras, como, sobre todo, a los caudillos locales y regionales; territorios escasa y desigualmente poblados pero dotados de ciudades-capitales fuertes (o que crecerán mucho en poco tiempo como Buenos Aires), lo cual favorece el centralismo de la capital; primacía del interés por parte de los grupos políticamente dominantes de consolidar el poder del Estado y no promover el desarrollo de la sociedad civil y la participación popular (al contrario, la mayoría de los ciudadanos quedan de LEGE o de FACTO excluidos del sistema político formal).

El Departamento del Sur de la Gran Colombia, mandada por el napoleónico y autoritario Bolívar, se caracterizó por su 'regionalidad'; es decir, por tres ciudades-regiones: Quito, Guayaquil y Cuenca, que dieron señas de identidad a todos sus habitantes, más allá de lo que los generales y encomenderos decidieron en Riobamba en 1830 al fundar la República del Ecuador. Para lo cual se continuó con la misma ley que, en 1827, promulgó Francisco de Paula de Santander, dividiendo el poder del Estado en términos territoriales entre departamentos, provincias y cantones, lo que inexplicablemente continúa hasta la actualidad completándose con nuevas instancias territoriales como las juntas parroquiales rurales, y agregándose, de acuerdo a la Constitución de Montecristi, las regiones, los distritos metropolitanos y las, hasta ahora no definidas, circunscripciones territoriales étnicas. Hasta la fecha las élites modernizantes y tradicionales, en su búsqueda de espacios de representación política, han conformado, por presión social, 24 provincias, 221 cantones, y tardíamente los sectores sociales, 789 parroquias rurales.

En la conformación territorial del Estado ecuatoriano confluyen conflictivamente, de una parte, una fuerte tradición de regionalidad (las localidades de Quito, Guayaquil y Cuenca) y municipalismo excluyente y de élites; y, de otra, un modelo de gestión y administración centralista del poder, que se consolida a partir de 1860 con García Moreno. 
Asimismo, para entender el proceso de fraccionamiento territorial del poder del Estado que se ha producido en el Ecuador, en estos 180 años de vida republicana, es necesario mencionar otros factores que influyen, a nuestro criterio, de manera determinante en éste. Un primer factor son las diferentes dinámicas y formas de empoderamiento local que generan tensiones y conflictos, pero que son inherentes al funcionamiento de un sistema de poderes tradicionales basado en el despojo y acaparamiento de la tierra agrícola y en la expoliación de la mano de obra indígena o mestiza empobrecida, y con diferencias dadas por la regionalidad de predominio urbano, como la que se vive en la Costa (elites económicas y comerciales) y en la Sierra (elites políticas e intelectuales). Alrededor de estas zonas se han legitimado escenarios de poder diferenciados y reforzado las disparidades territoriales. Las pugnas por las hegemonías regionales y por el predominio de poderes enquistados en estas elites locales podrían explicar el fracaso o el logro efectivo de las políticas de modernización del Estado, como las descentralizadoras.

Otro factor a tenerse en cuenta es la urbanización tardía pero creciente de las redes de ciudades que ha generado en ellas una serie de instituciones que conforman el poder local. Entre éstas se distinguen del lado del Estado: el Gobierno Municipal, el Gobierno Provincial, y, actualmente, las Juntas Parroquiales Rurales; como también los aparatos especializados del Estado presentes en las capitales de provincia o cabeceras cantonales; del lado de la sociedad civil: los centros agrícolas, artesanales, colegios profesionales, partidos políticos, comités barriales, organizaciones pro-vivienda, cooperativas, asociaciones de empleados y sindicales, cámaras de comercio, asociaciones de comercio y servicios, asociación de choferes y transportistas, asociación de estudiantes, etcétera.

Así podemos concluir que existe una gran fragmentación del poder local, lo que está en relación directa con el nivel de complejidad de la economía y de su área de influencia, así como también a la diversificación y dinamismo de su hinterland agrícola; a lo que se agrega, el poco desarrollo del capital social en estos territorios — en la acepción dada por Robert Dahl—, lo que incide en la gran debilidad organizativa de los sectores subalternos, salvo en las áreas donde la existencia de conflictos agrarios permitió el desarrollo de organizaciones campesinas que estuvieron conformadas, principalmente, por militantes de 
los partidos Socialista o Comunista; mientras que en los dos centros primados (Quito y Guayaquil) y en algunas ciudades intermedias (Manta, Ambato, Cuenca, entre las más significativas) se han producido procesos de industrialización basados en la sustitución de importaciones o agroindustrias, lo que permitió el desarrollo de organizaciones obreras, lamentablemente débiles y con baja capacidad de interlocución social.

En esta estructura, predominantemente urbano-agrícola, se han ido desarrollando unas redes heterogéneas de centros urbanos, entre los que se distinguen: a) Algunos de carácter regional-metropolitano como Quito y Guayaquil, que han podido adquirir una cierta autonomía relativa y desarrollar sus propios circuitos de acumulación, que van a tener una preeminencia específica en los procesos políticos y electorales como consecuencia de las poblaciones que engloban, alrededor de $1 / 3$ del total nacional; $b$ ) Las ciudades denominadas 'intermedias', que han tenido gran crecimiento urbano y económico desde la segunda mitad del siglo XX, logrando un desarrollo exógeno generalmente vinculado a la demanda externa de origen agrario, caso del cacao, banano, café o caña de azúcar; además, muchas de estas ciudades, por las diferentes coyunturas de crisis del modelo agroexportador, no han podido completar una serie de mutaciones y funciones urbanas, por lo que todavía mantienen características agropecuarias, pero articulando relaciones asimétricas entre el campo y la ciudad; $\mathrm{y}, c)$ Las ciudades secundarias que en general son centros poblados con menos de 50 mil habitantes, que están muy vinculadas a territorios predominantemente rurales y agropecuarios, $y$, en muchos casos, sirven como ciudadesdormitorio de los sectores sociales campesinos o de los asalariados agrícolas, ya que en estos centros poblados, aún con las carencias de servicios que tienen, se vive mejor que en el campo, sobre todo porque se accede a educación, salud y abastecimiento.

Por último, en el prolongado y recurrente contexto de crisis económica, política y social del país, debemos indicar de forma resumida las características fundamentales y el patrón de funcionamiento de los gobiernos locales existentes en las urbes ecuatorianas, para poder apreciar mejor las estrategias diseñadas y los enfrentamientos políticos y electorales que se dan, tanto entre los grupos citadinos como entre las fracciones sociales que se constituyen al interior de cada aparato de estos gobiernos. 
Los gobiernos locales (juntas parroquiales-municipio-prefectura), en tanto copartícipes de las formas particulares que asumen las relaciones Estado-sociedad, se manifiestan de diferentes formas y situaciones en las ciudades ecuatorianas, lo que es imputable a una amplia gama de factores, tanto históricos como políticos y económicos, que configuran la personalidad de cada administración local. En la actualidad existen en las cuatro regiones geográficas 24 prefecturas, 221 Municipios y 789 parroquias rurales, los que gozan de una 'autonomía sin independencia'; es decir, son dependientes de las rentas que les transfiere el gobierno central, hasta en e1 $65 \%$ de sus presupuestos; esta situación, entre otras causas, configura las limitaciones financieras, técnicas, administrativas y políticas de estas instituciones del poder local.

Es importante mencionar que entre los principales problemas se destacan los siguientes: 1. La pérdida paulatina de sus funciones específicas, las que se limitan o recortan hasta que se hagan responsables exclusivamente de las 'externalidades' del desarrollo - instancia administrativa dispensadora de servicios-, pero no del desarrollo mismo de la ciudad y de los territorios pertenecientes a su jurisdicción, lo que hace que se lo defina y oriente en función clientelar. Por regla general estas funciones disminuidas son asumidas por el Estado central, lo que se ha agudizado más en la actualidad. 2. Lo anterior hace que en la gestión local se presente una situación de atomización, tanto en términos institucionales como legales, lo que en la mayoría de casos producen trabas y bloqueos a las actividades de estos gobiernos. 3. En estas unidades territoriales es mucho más marcada la carencia de cuadros técnicos en las administraciones respectivas, por la falta de una visión política y de gerencia social en los gobernantes locales, que los hace funcionar permanentemente entre actitudes electorales y paternalistas-clientelares. 4. La existencia de varias instancias de poderes locales, como los niveles administrativos regionales, provinciales y locales propiamente dichos, presentan frecuentemente una serie de conflictos políticos e institucionales, que en el fondo no son otra cosa que la manifestación de las contradicciones entre fracciones de los bloques de poder en los gobiernos locales.

En este escenario descrito, los líderes políticos locales han asumido y desarrollado una misma matriz de socialización — como lo reseña Gramsci-, que los ha condicionado. Por un lado, la internalización y prácticas de unos modos 
de vivir y de pensar, tanto en lo privado como en lo público, que reproducen las formas de dominación y autoritarismo que caracterizan a estas sociedades tradicionales y predominantemente agropecuarias. A lo que se agregan una mentalidad patrimonialista, dada por la procedencia social y riqueza amasada y a la existencia de la agenda propia, y el auto percibirse desde un mesianismo insostenible como consecuencia de las relaciones políticas desarrolladas con los otros niveles territoriales de distribución del poder del Estado, con los que negocian apoyos políticos y económicos de doble vía, para impulsar las empresas electorales y fortalecer las tiendas políticas - como las denomina Amparo Menéndez-Carrión.

Lamentablemente, los cambios ocurridos en la década de los setenta, y posteriormente con la modernización agropecuaria en el agro, tampoco afectaron substancialmente las relaciones económicas y políticas de la región. Lo que nos plantea la relación entre mentalidades, cultura y cultura política en nuestras localidades, tanto andinas como costeñas, como lo destaca Xavier Andrade:

Recordando también que en los escenarios locales de poder, antes del cacao y después con el banano, (re)apareció un nuevo actor al que se le atribuirá un papel protagónico en la opresión étnica-social: el gamonal. Término que pasaba a designar a un mediano propietario que ejercía el poder local en términos reales, independientemente de que disponga o no de un cargo público. El gamonal era, entonces, el poderoso que gozaba de una autonomía parroquial, aunque subordinado políticamente a las aristocracias regionales; era un producto del ascenso social, donde lo político se expresaba directamente relacionado con los mecanismos de funcionamiento económico, que daban la vinculación entre la mediana propiedad rural y ciertas formas del capital comercial. Al respecto debemos resaltar que todos los líderes locales costeños estudiados son propietarios territoriales rurales y están íntimamente vinculados a los grupos sociales terratenientes, los cuales casi siempre colaboran en sus empresas electorales o hacen parte de sus tiendas políticas.

El enfrentamiento entre los 'viejos' partidos, así como la facilidad con que decaen y se fortalecen los nuevos en una suerte de fatalismo político y de ines- 
tabilidad institucional, nos da unas pautas de adhesión de la clientela electoral, facilitadas por el entorno legal y cultura política vigentes que hemos heredado del clientelismo ejercido por los caudillos locales y nacionales, históricamente. Debemos recalcar que la actividad política de estas élites locales está estrechamente relacionada, preferentemente, con partidos políticos nacionales, así tenemos que desde el segundo velasquismo, en 1944, ya había 7 partidos entre los que destacamos el Liberal, Conservador, Socialista, Comunista, Alianza Política Ecuatoriana-ADE — antecedente de la CFP—, Frente Democrático Ecuatoriano - antecesor del PSC_-, Vanguardia Socialista Revolucionaria y, obviamente, el Movimiento Velasquista. A los que se agregan actualmente partidos políticos ya en crisis como la Democracia Popular- Democracia Cristiana, Izquierda Democrática, Partido Renovador Institucional Acción Nacional (PRIAN), Sociedad Patriótica, Pachakutik, Movimiento Patria Altiva y Soberana (PAIS), PRE, MPD, entre los más importantes.

Tanto las viejas como las nuevas tiendas partidarias, con el pragmatismo que les caracteriza a sus empresas electorales hasta la actualidad, aplicando esa lógica perversa, elemental y primitiva de que "en la guerra, el amor y la política todo está permitido", continúan con los baratillos de oferta por toda la geografía nacional cooptando adherentes y votos con el fin de triunfar, sin tener en cuenta las demandas sociales o un mínimo plan programático, inclusive los partidos que se auto califican de ideológicos han tenido que recurrir a esta artimaña para ser beneficiados con el voto popular.

Los elementos anteriores nos sugieren que los mecanismos de reclutamiento electoral y de adhesiones se hacen siguiendo un esquema extra-político, y por ende no partidario, en la mayoría de los casos los mecanismos de articulación del apoyo electoral se da a través del compadrazgo, amistades, vinculaciones familiares y laborales y hasta por uniones afectivas-maritales. Pero también se recurre a la compra de los votos a través del reparto de fundas de alimento, reuniones bailables y espectáculos artísticos, amedrentamiento y violencia manifiesta de guardaespaldas o 'destajeros'.

Al constatar los nombres y apellidos de los líderes políticos locales encontramos, en primer lugar, que muchos de éstos se alternan y generalmente aparecen participando en diferentes partidos al de su inicio, situación que nos permite entender la proliferación de 'camisetazos' y cómo se cooptan los diri- 
gentes. Y, en segundo lugar, resaltamos que generalmente estos líderes son candidatizados desde los centros primados, y son ellos, como individuos, los que conforman las listas para los puestos locales, lo que hace que automáticamente "el Partido sean ellos como personas en sus localidades".

Un rasgo interesante a destacar es la gran movilidad en la ocupación de las dignidades locales que se da entre la dirigencia política de estas ciudades, sus representantes se alternan como concejales, consejeros, diputados o asambleístas, alcaldes o prefectos; un mecanismo que les permite perpetuarse en la estructura del poder local o provincial y estar vinculados al Estado central con cualquiera que fuese el régimen de turno.

Es importante destacar las diferencias que se plantean entre candidaturas de individuos y/o de listas. Generalmente las candidaturas unipersonales, según lo observado y los informantes calificados, se basan principalmente en los atributos del postulante que la encabeza y secundariamente en el aparato partidario; lo que hace que en estos casos las adhesiones políticas se hagan a la persona antes que a su ideología o plan de acción. Además, esta situación se evidencia cuando se cruzan los resultados obtenidos por una candidatura unipersonal con los obtenidos por la lista pluripersonal en una provincia o en un cantón dado. Que, a su vez, nos devela la existencia de una estructura de estratificación social entre las elites políticas del cantón, la cabecera cantonal y el centro primado regional/nacional.

La construcción y consolidación del Estado unitario en el Ecuador se da durante el boom petrolero y la diversificación agropecuaria, que va desde el inicio de la década del setenta hasta la fecha. Durante esta crucial etapa del proceso de modernización tenemos dos fases; la primera, caracterizada por el desarrollo de la producción petrolera y el incremento sostenido y creciente de los precios internacionales del crudo, consecuencia del conflicto israelita-palestino y la constitución y accionar del cartel de la OPEP. Con la monetización de los petrodólares se afirman todos los cambios, positivos y negativos, antiguos y nuevos, iniciados en las tres décadas anteriores, en particular: la ampliación de los estratos medios, desarrollo de un sector bancario-financiero e industrialización por sustitución de importaciones, la urbanización acelerada de la economía nacional, la diversificación del sector agropecuario, el crecimiento desmesurado 
de la deuda externa, la expansión del sector servicios y nuevas formas de organización y protagonismo de los sectores populares y sociales, entre otros.

En este contexto, al inicio del auge económico, se produjo una radicalización de los conflictos sociales y políticos existentes que provocaron que las Fuerzas Armadas, una vez más como institución, "asumieran las tareas de gobierno, en febrero de 1972, anunciando la ejecución de un programa de reformas sustanciales como la agraria (Nueva Ley de Reforma Agraria), la tributaria y un conjunto de acciones de beneficio popular, a fin de lograr reorientar la sociedad ecuatoriana para que dejara de ser económicamente subdesarrollada, socialmente injusta y políticamente dependiente" (Nueva Historia, Vol. 11, p. 69); como destacaba el Plan de Transformación y Desarrollo del Gobierno Nacionalista y Revolucionario de las FF.AA.

Hasta 1974 se habían formado 114 cantones; para 1982 ya existían 126 cantones en las 20 provincias vigentes.

Después de una década de alto crecimiento económico y de desigual distribución social de la renta petrolera se inauguró una creciente y profunda crisis económica, en 1982, provocada por la deuda externa y la moratoria mexicana, la caída de los precios internacionales de nuestras materias primas y, como golpe de gracia, las pérdidas sufridas por el fenómeno de El Niño 1982-83, cuya reconstrucción dura hasta la fecha, y que se ha profundizado por las condiciones de las políticas económicas promovidas y obligadas por los organismos financieros multilaterales (FMI, BID, BIRF y CAF), con la aplicación, única e infalible, del ajuste estructural, que han acrecentado, a niveles nunca antes conocidos en la historia republicana, la pobreza y la miseria de crecientes grupos sociales del campo y la ciudad.

Se produjo también un gran crecimiento del Estado, tanto de la administración pública como de las empresas estatales, o con algo de inversión estatal (hasta 1970 existían 55 empresas estatales; para 1990 había un total de 163, que comenzaron a fracasar y liquidar durante el ciclo de crisis, o están siendo sometidas a situaciones de privatización, principal leitmotiv de la reforma del Estado). Asimismo, este Estado unitario y centralista en crisis se ha manifestado territorialmente al contar con 169 cantones en 1990 a 22 provincias y 217 cantones a la fecha, a los que se agregan 789 juntas parroquiales rurales, alrededor de 564 comunas de 15 etnias y nacionalidades como circunscripciones 
territoriales a definirse, como en una serie de contenciosos limítrofes internos y demandas agresivas para constituir nuevas provincias y cantones, para acceder más fácil y directamente a los beneficios del presupuesto fiscal.

Es en este contexto de democracia formal y restringida, como de profunda crisis económica y social del país donde, frente a la incapacidad del Estado unitario y centralista, proliferan de manera creciente las demandas y discursos sobre la reforma del Estado y la descentralización y autonomía, pero sin el apoyo social y unos elementos propositivos viables, como lo veremos a continuación.

Finalmente, a pesar de que el país creció en términos económicos y ha avanzado en el desarrollo de sus estructuras básicas, quedaron muchos problemas por resolver y otros que se agudizaron debido al mismo facilismo financiero reinante en la época. Todos ellos se incrementaron como consecuencia de las crisis subsiguientes e, inclusive, muchos de los indicadores sociales retrocedieron a niveles de los años sesenta, lo que hace posible hablar de una década pérdida y del desarrollo como un mito.

Desde 1974 hasta la fecha el territorio nacional se ha fraccionado mucho más - como ya lo hemos señalado en las páginas precedentes-: en estos 36 años han aparecido 4 nuevas provincias y 107 cantones; las élites locales han hecho todo lo posible por participar en el "botín" que significa poder acceder más fácilmente a representaciones políticas sin tener que recurrir a los favores de los patriarcas políticos asentados en los centros primados y en las cabeceras provinciales. Falta por ver los impactos que en los gobiernos seccionales tendrán las nuevas propuestas de la Constitución de Montecristi de 2008 y la aplicación del Código Orgánico de Ordenamiento Territorial, Autonomías y Descentralización (COOTAD), partes del proyecto de estatalidad que ya están provocando pesadillas con varios de sus componentes positivos como son la rendición de cuentas y la revocatoria del mandato.

Resulta altamente preocupante, en la actual coyuntura, el inicio de la segunda fase con el paso del Estado unitario en crisis al desarrollo de una estatalidad basada en la reorganización autoritaria y clientelar del Estado y de sus componentes territoriales y el anti partidismo (partidocracia, según la jerga descalificadora del correísmo) impulsados desde el gobierno, cuyas otras características son el no identificar plenamente los conflictos existentes y, por 
ende, calificar cualquier protesta social como una conspiración, manipulando a los sectores sociales y promocionando una represión anti democrática, o por la judicialización de la política con las actitudes y prácticas de esos "ángeles vengadores buñueleanos" como son la Fiscalía y el Consejo Nacional de Justicia, consolidando el proyecto estatalista calificado por Correa como Socialismo del siglo XXI.

De la larga noche neoliberal al neo-constitucionalismo en gestión territorial y descentralización

Si los procesos de modernización y transformación del Estado afectaron en general las formas y estrategias convencionales de gobernabilidad en el continente, las políticas descentralizadoras contribuyeron específicamente a fortalecer la presencia del Estado en el ámbito local, a expandir los sistemas políticos y la representación política en territorios antes aislados, a situar en la escena pública a nuevo actores, antes excluidos, así como a reforzar la presencia local de las empresas privadas, sociales y comunitarias. Aun así, una cosa es expandir el Estado y el mercado y otra cosa es desconcentrar y descentralizar su poder y administración; y es allí donde queda una de las grandes deudas de la descentralización en la 'glocalización' con la sociedad y la modernidad.

A partir de 1996 se agudiza la crisis del tipo de Estado que comenzó con las crisis de 1982, donde se expresó de la manera más clara el agotamiento e incapacidad del Estado central para enfrentar los problemas nuevos y estructurales de la formación social ecuatoriana. Desde 1982 se produjo la coincidencia de tres circunstancias:

Primero, las rupturas 'blancas' y, desde el Congreso, del orden constitucional con la destitución de tres presidentes elegidos democráticamente, recurriendo a argucias y motivos no señalados en la Carta Magna, provocando una inestabilidad política que hace que a estos 14 años correspondan igual número de presidentes en el poder, incluyendo al actual. Lo que, obviamente, también repercutió en los gobiernos seccionales.

Segundo, la convocatoria a Asambleas Constituyentes y la promulgación de Constituciones 'garantistas' como la de 1998 y la de 2008. En ambos casos éstas quedaron como simples leyes de papel, ya que ni se respetaron ni se aplicaron, particularmente en lo relacionado a la temática que estamos desarrollan- 
do, sino que se usaron de acuerdo a la discrecionalidad del presidente o de los intereses de las mayorías móviles legislativas.

Tercero, la conjugación nociva de las dos anteriores situaciones, por la dinámica social existente en el país y por los adustos y cuasi perpetuos liderazgos políticos existentes, fragilizaron mucho más el sistema nacional de partidos políticos; que se vio superado, de un lado, por la creciente y recurrente insurgencia de 'outsiders'salidos del mismo, como los casos del coronel Gutiérrez, Álvaro Noboa y Rafael Correa; y, de otro lado, por el desarrollo de nuevas prácticas políticas y electorales impulsadas por los movimientos políticos provinciales y cantonales, facilitadas por los cambios constitucionales y legales.

\section{Fortalecimiento y éxitos relativos de los regímenes seccionales en el país}

De acuerdo a las nuevas tendencias del desarrollo humano, los gobiernos descentralizados deben constituirse en impulsores y gestores del desarrollo local, tanto porque deben cumplir con las funciones que están ligadas a las principales necesidades sociales de la población como al saneamiento ambiental, alumbrado, construcción de vías, parques, seguridad ciudadana, etcétera; así también de garantizar la movilización local de recursos y la adopción real de estrategias para asegurar un crecimiento económico sostenible y sustentable, en beneficio de las grandes mayorías ciudadanas a partir de gobiernos de cercanía.

En los últimos años, muchos de los gobiernos locales ecuatorianos han emprendido un proceso de renovación y modernización de la gestión administrativa, de los servicios y las obras públicas que están beneficiando a la mayoría de sus colectividades. Los avances logrados hasta la actualidad han sido reforzados con un mejoramiento de la gestión y el impulso de procesos de cambios en la dimensión territorial y local, lo que "permitiría: a) Ampliar el campo de derechos y libertades; b) Incorporar a los sectores excluidos en instituciones representativas; y, c) Viabilizar un mayor control y participación populares en la actuación de las administraciones públicas" (Borja, 1987b); o de transferencia de competencias, como lo resalta Sergio Boisier, para quien "la descentralización es el traspaso de poder de decisión a organismos, entidades e instituciones. La misma puede combinar dimensiones funcionales, territoriales o políticas. 
Puede implicar además transferencia de funciones, atribuciones, responsabilidades y recursos financieros, materiales y tecnológicos desde las entidades de la función ejecutiva hacia los gobiernos seccionales". No obstante, una cosa es lo que dice la teoría sobre la descentralización y, otra, la que acontece efectivamente en el concierto ecuatoriano, que es el que analizaremos en este texto. Por eso, por momentos, lo que se evidenciará es una permanente tensión entre transferencia o delegación de funciones - pero con problemas serios en la asignación de recursos y del tipo de funciones delegadas - y deslocalización de actividades administrativas sin mayores poderes de decisión.

Inclusive, durante esas dos conflictivas y problemáticas décadas (ochenta y noventa) donde se expresó de manera creciente la profunda crisis del Estado central y la implantación paulatina de su achicamiento, particularmente durante las administraciones de Durán- Ballén, Bucaram y Mahuad, íconos de "la larga noche neoliberal"; pero también se presentó una serie de experiencias relativamente exitosas de varios gobiernos seccionales: la administración de Rodrigo Paz en Quito, la de Fernando Cordero en Cuenca, Bolívar Castillo en Loja, Jorge Zambrano en Manta, Julio Touma en Babahoyo, Rafael Callejas en Ambato; y las que se producen en Guayaquil con León Febres-Cordero y Jaime Nebot, desde 1992 hasta la actualidad; que ha permitido la conformación de un modelo de gestión que ha sido seguida por alcaldes socialcristianos en el que se destacan los casos de Machala, Quevedo, Daule, entre otros centros poblados. Al respecto, amerita reseñar los casos de las administraciones indígenas locales: Auki Tituaña en Cotacachi, Conejo en Otavalo, Curicama en Guamote, Umajinga en Cotopaxi, entre otras. Hay otros prefectos que se han distinguido: Montgomery Sánchez en El Oro, Salvador Quishpe en Zamora, Jorge Marún en Los Ríos, entre otros.

Pero lamentablemente, salvo en el caso relativo de Guayaquil, en la mayoría de los mencionados no ha habido una continuidad administrativa en lo relacionado a planes, políticas y proyectos; como tampoco en lo concerniente al fortalecimiento de la institucionalidad de estos gobiernos descentralizados; no hubo facilidades políticas para impulsar su gobernabilidad democrática, como lo veremos a continuación. Inclusive, en el COOTAD, recientemente aprobado, no se impulsan mecanismos y estímulos para superar las crisis institucionales 
de los gobiernos autónomos descentralizados ni para enfrentar las causas que las provocan.

La situación actual de los gobiernos seccionales: caudillismos locales, problemas en la gestión de sus instituciones y rendición de cuentas-revocatoria del mandato.

En la Constitución Política de 1979 se señalaba que el Estado ecuatoriano es unitario y descentralizado, pero desgraciadamente no pasó de ser una simple declaración retórica, sin ninguna incidencia real en la organización territorial estatal y sus prácticas. Posteriormente, se convirtió en un discurso electoral, en particular durante las campañas presidenciales últimas, y una demanda, inconstante e inconsistente, planteada por ciertas élites locales, principalmente de Guayaquil, y de ciertas cabeceras provinciales de la Costa y la Sierra, en restringidos cenáculos políticos de marcado sesgo regionalista, enfrentados en múltiples niveles entre los componentes de la bicefalia nacional, la capital nacional y las provincias, la capital económica y las capitales de provincias de su área de influencia, entre la capital provincial y sus cantones, entre la municipalidad y las recién conformadas juntas parroquiales rurales, etcétera.

No obstante, este conflictivo escenario, de desencuentros y fragmentación, sí permitió que cuajen algunos logros legales como la Ley Especial de Distribución del 15\% del Gobierno central para los Regímenes seccionales (marzo de 1997) y, más tarde, la Ley Especial de Descentralización del Estado y Participación Social (octubre de 1997). Ambos instrumentos legales han sido aplicados ocasional y parcialmente, lo cual es imputable a: 1) La ausencia de una real demanda social y popular por la descentralización efectiva; 2) Al manejo manipulador e interesado del tema por parte de ciertos grupos políticos; y 3) La inexistencia de un liderazgo político que desde la conducción del Estado nacional impulse y dirija el proceso de descentralización como su política.

A los documentos legales reseñados se agrega, más tarde, la nueva Constitución Política de 1998, dictada por una Asamblea Constituyente que planteó un conjunto avanzado, pero incompleto, de preceptos constitucionales de profundo contenido social y territorial, que fueron paulatinamente impulsados, según correlación de fuerzas legislativas y cálculos políticos del Ejecutivo: Ley Orgánica de las Juntas Parroquiales Rurales de octubre de 2000; Reglamento a la Ley de Descentralización del Estado y Participación Social y Plan Nacional 
de Descentralización; y más tarde, la ley Orgánica de Régimen Municipal, en septiembre de 2004.

En este contexto neoliberal de cambios formales incipientes, a niveles institucionales y legales, de la arquitectura estatal se debe destacar el Art. 225 de la Constitución Política de 1998 que señala que, "el Estado impulsará mediante la descentralización y la desconcentración, el desarrollo armónico del país, el fortalecimiento de la participación ciudadana y de las entidades seccionales, la distribución de los ingresos públicos y de la riqueza".

"El gobierno central transferirá progresivamente funciones, atribuciones, competencias, responsabilidades y recursos a las entidades seccionales autónomas o a otras de carácter regional. Desconcentrará su gestión delegando atribuciones a los funcionarios del régimen seccional dependiente". Estos elementos específicos de la descentralización o autonomía han sido poco aceptados o comprendidos por los actores políticos y sociales, entre otros factores, por la escasa difusión y compresión social de los mismos como por privilegiar el interés particular por sobre el interés público; pero salvo un conjunto reducido de gobiernos locales, prefecturas y municipios han asumido algunos de los derechos mencionados en términos concretos y algunas competencias específicas de acuerdo a sus situaciones particulares; el resto lo ha hecho según lo planteado y decidido por el gobierno central, de acuerdo a cálculos políticos del momento, como las transferencias de competencias en ambiente, educación , turismo, vialidad y agricultura que, hasta el momento, no se han cristalizado debido a la actitud del propio Estado central, que intenta transferir a los regímenes seccionales lo menos importante; lo cual dilata el proceso y lo torna engorroso, más allá de las cinco consultas provinciales realizadas y las violaciones constitucionales y legales incurridas por los componentes del Estado.

Aún en la actualidad, con el tiempo transcurrido y la promulgación de la Constitución de Montecristi en 2008, cuyo Título XI: "De la Organización Territorial y la Descentralización”, que cuenta con 17 artículos —el más completo en la larga historia constitucional ecuatoriana-, todavía provoca grandes divisiones y desencuentros como se ha podido observar en las discusiones públicas convocadas por la Asamblea y en sus debates para la aprobación del COOTAD. 
En esta parte vale destacar que esta Constitución se ha desarrollado aspectos positivos, que existiendo ya en la de 1998 nunca fueron respetados por los dignatarios, como son la rendición de cuentas y la revocatoria del mandato, principalmente; que el proyecto estatalista nunca pensó que se le iba aplicar, ocurriéndole la suerte del 'cazador cazado'. Así en el caso del Art. 105, que plantea la Revocatoria de Mandato que, según el Consejo Nacional Electoral, a la fecha registra 260 pedidos de formularios para la recolección de firmas que se desglosan de la siguiente forma: Un formulario solicitado para la revocatoria del Presidente de la República, otro para el Presidente de la Asamblea Nacional, tres formularios para prefectos, sesenta para alcaldes (que corresponden al $27 \%$ de todo el Ecuador) y ciento noventa y cinco para concejales (que hacen el $88 \%$ de los Concejos del país).

Las cifras mencionadas y las declaraciones dadas por los afectados a los medios de comunicación nos permiten la siguiente lectura: 1. La mayoría de los gobernantes locales bajo solicitud de revocatoria señala que son acusaciones de sus enemigos políticos o de los perdedores que quieren sus cargos. 2. Las revocatorias se han presentado en la mayoría de cantones representativos de la tipología de ciudades ecuatorianas, no se han salvado ni Guayaquil ni Quito. 3. Los acusadores señalan que solicitan la revocatoria de los mandatos por incumplimiento de los planes de trabajo, incapacidades manifiestas, o graves acusaciones de corrupción y, 4. Esta situación nos demuestra la fragilidad de la gobernabilidad democrática a nivel local como consecuencia del estatalismo en ciernes y la no solución de los viejos problemas históricos reseñados en este trabajo.

Al respecto, podemos resumir que la conducta institucional practicada por los regímenes seccionales con relación a la transferencia de las competencias ha sido dual, lo que ha hecho que desde el imaginario popular se lo asuma como una dádiva y entrega 'a cuentagotas' por parte del gobierno central; y que éstos sólo quieran las transferencias de rentas y no las responsabilidades que éstas conllevan, según los sondeos de opinión realizados. A lo que se agregan, la indecisión del gobierno central y la posición regateadora de la administración pública, en particular de los cuadros tecno-burocráticos e intermedios, y que más del $70 \%$ de los municipios existentes se han constituido de una manera ilegal, ya que no cumplen con los requisitos legales y técnicos para funcionar como un cantón; asimismo, de acuerdo a la Asociación de Municipalidades del Ecuador 
(AME), sólo el 20\% de los municipios del país tienen capacidades para asumir convenientemente sus funciones, como la gestión y administración. Inclusive, sobre las juntas parroquiales rurales puede decirse que aún se encuentran en la búsqueda de un reconocimiento social efectivo y operativo por parte de los consejos provinciales y municipios; la mayoría de éstos las perciben y sienten como competidores electorales y depredadores de los escuálidos presupuestos fiscales locales, lo que ha hecho que hasta el momento no se hayan integrado dinámicamente en la trama del poder local-provincial y urbano-rural.

Todos los factores reseñados, como otros no citados, hacen que la mayoría de los Gobiernos Autónomos Descentralizados - como los denomina el actual gobierno - todavía analicen qué áreas asumirán, lo que resalta la precariedad institucional y las limitaciones políticas del clientelismo local, como la miopía de las elites, y confirma la ausencia concreta de apoyo social. Resaltando que los problemas no se resuelven sólo con leyes, sino que hacen falta institucionalidad, estabilidad, financiamiento sin condicionalidad, promoción del talento humano, fortalecimiento técnico-administrativo, entre los aspectos más destacados.

Sobre la base de la legislación descentralizadora vigente, que existe en demasía pero como letra muerta, que ha sido aplicada parcialmente por algunos gobiernos locales, pero que con decisión política han iniciado un proceso de descentralización en sí, ya sea negociando políticamente con el Ejecutivo o 'haciendo autonomía al andar', desarrollado una gama de experiencias locales y provinciales relativamente exitosas, que nos permiten construir una tipología del actual accionar de la gestión local - de los gobiernos provincial y municipal- como proyecto histórico-político en la coyuntura: 1. Los gobiernos seccionales de gestión indígena, casos de Cotacachi, Otavalo y Guamote; 2. Los gobiernos locales negociadores y promotores de lo público-estatal como los de algunas ciudades intermedias, casos de Cuenca, Quito, Esmeraldas y Loja; 3. Los gobiernos seccionales con una gestión empresarial y verticalista, como en los casos de los municipios de Manta, Guayaquil, Machala o la Prefectura del Guayas, y, finalmente, 4. Los gobiernos locales de gestión clientelar y populista predominante, sin ninguna aspiración al cambio, que son, desgraciadamente, la gran mayoría.

En fin, estas decididas y diversas propuestas emprendedoras de los gobiernos autónomos descentralizados están marcando un derrotero significativo a se- 
guir, o ser tenido en cuenta, coordinadamente por el Estado, el sistema político y la sociedad civil en el Ecuador.

Asimismo, vale destacar el caso especial de Guayaquil, a inicios del siglo XXI, como un centro primado nacional, que presenta la continuidad y los logros relativos de su administración municipal, desde 1992 hasta la fecha, que tiene el reconocimiento incluso de parte del PNUD que, en diciembre del 2003, lo reconoce como una "notable experiencia en el campo de la gobernabilidad local y de transformación de la urbe"; destacando que ha comenzado a asumir su 'cosmopolitización' de puerto internacional (marítimo y aéreo) en la geopolítica del Pacifico Sur y de la Cuenca del Pacífico. Para el complejo y desconocido escenario de la globalización se ha desarrollado y planificado en esta última década un conjunto de obras urbanísticas y modificaciones institucionales que ha marcado su desarrollo local y el de sus actores, pero sin definirse y consensuarse un proyecto histórico de ciudad y de encadenamiento productivo como región incluyente. Este desarrollo urbano se ha basado en un enfoque tradicional y en una ortodoxia urbanística, como el regreso y recuperación de la ciudad construida, principalmente de los bienes patrimoniales, paisajes y áreas edificadas deterioradas del casco comercial y sus alrededores. No sólo es una simple operación de negocio inmobiliario, sino también la creación y desarrollo de un creciente espacio público, léase 'colectivo', para uso y disfrute de los usuarios de la ciudad pero desde una lógica clientelar. Así también los sustentos de la Regeneración Urbana y de Malecón 2000, entre otros, como programas de renovación urbana de la Municipalidad, que explican cómo se construye, real y simbólicamente, la ciudad desde una práctica de dominación, y cómo se entretejen las políticas urbanas y la dinámica social elitista del poder local.

A lo anterior se agregan las modificaciones institucionales que se han producido y han logrado la recuperación de la autoestima ciudadana, como recurso ideológico, rescatando no sólo ciertos derechos sino también las obligaciones, como la implantación de una cultura tributaria. Aunque las políticas urbanas reseñadas no impiden reconocer la existencia de otros programas: la institucionalización de una política social con la creación del Departamento de Acción Social y Educación (DASE); la Corporación de Seguridad Ciudadana, que debe superar el enfoque predominantemente represivo y asumir una estrategia basada en la prevención y disuasión de las violencias sociales, entre otros. Como 
diría Henri Lefebvre: "todavía no se ha logrado para todos los habitantes de la aglomeración el derecho a la ciudad", ya que hay un recrudecimiento de la pobreza, las desigualdades y el desempleo y subempleo, que agudizan las inequidades, la inseguridad y el miedo en la urbe.

La mayoría de los dirigentes políticos tradicionales, ya mencionados, desarrolló sus actividades influenciados por varias circunstancias del pasado reciente: por un lado, el largo periodo de liderazgo político nacional del cinco veces presidente (entre 1934 y 1972), José María Velasco Ibarra, con un gran liderazgo carismático — como lo definía Weber-, y por otro, en este último periodo constitucional, por las figuras de un puñado de dirigentes de partidos que no permitían la alternabilidad en sus tiendas políticas, salvo que la muerte u otros factores los desapareciera de la escena pública, como Febres Cordero, Borja, Bucaram, principalmente; y también por la última dictadura institucional de las Fuerzas Armadas (1972-1979), que ha sido la más larga de nuestra vida republicana. Pero, a nuestro criterio, muchos han sido relevados por los nuevos liderazgos locales y tiendas partidarias, que actúan de una manera diferente pero siempre de forma clientelar e inmediatista, a partir de la nueva etapa constitucional que se estrenó en 1998 y que se vuelve a dar en 2009, con una Carta Magna garantista y estatalista, y que dura hasta la fecha con el gobierno de la revolución ciudadana. Esto permite entender también la simbiosis que siempre se ha dado entre el líder nacional-partido político, en Carondelet o en el poder, y los líderes locales en sus ciudades y provincias, más en las circunstancias actuales con el crecimiento geométrico del precio del barril de petróleo y el manejo clientelar del Banco del Estado a través del programa Promadec, que permitió la compra de lealtades electorales y de afiliaciones partidistas de gobernantes locales que coadyuvó a que el movimiento PAÍS se convirtiera en la primera fuerza política del Ecuador.

\section{Perspectivas}

Hemos planteado y descrito algunos elementos generales para el funcionamiento de los sistemas sociales, urbano-rurales y políticos de las provincias y cantones ecuatorianos, relacionados a las élites políticas locales y a los comportamientos políticos y electorales de los ciudadanos e instituciones locales que 
traducen la existencia de escenarios en los que se tejen formas de dominación y hegemonía política, así como también de estructuras partidistas clientelares y alianzas inéditas y 'contra natura', mecanismos de reclutamiento disímiles como también prácticas de control social violentistas-represivas y actitudes autoritarias y antidemocráticas de los líderes y sus secuaces.

Pensamos que en estas unidades territoriales las crisis económicas del país hacen que se sobredimensione la crisis social e institucional más que en otro tipo de asentamiento o aglomeración, como consecuencia de la escasa o débil presencia del Estado y del mimetismo político de las élites, lo que ha hecho que todos los partidos - sin excepciones - hayan empleado mecanismos de articulación de apoyo electoral de tipo eminentemente clientelar y populista, impidiendo la madurez política del electorado y profundizando el foso entre sociedad civil y sociedad política, bloqueando cualquier posibilidad de instaurar un nuevo estilo político, democrático y deliberativo en la conducción de la administración local o en la elección de los candidatos nacionales. En esta perspectiva, inclusive se producen situaciones de marcada ineficiencia e ineficacia de los organismos técnicos-administrativos, a lo que se suman situaciones de corrupción e impunidad, como lo destacan los mecanismos de control del Estado y los medios de comunicación en la actualidad.

El modelo político imperante, con todos los cambios que han ocurrido en estos últimos 30 años de retorno al régimen de derecho, sigue basándose en el clientelismo y populismo como principios centrales de la acción política impidiendo con ellos el establecimiento de sólidos partidos políticos y de liderazgos realmente comprometidos con el cambio social e institucional, a lo que se agrega el escaso desarrollo y difusión de una cultura política y cívica por parte de los actores implicados. Pero que en este momento está pasando del anacrónico Estado unitario en crisis a un estatalismo, que está llevando adelante una confusa reforma que no es otra cosa que 'el cambiemos algo para que no cambie nada', que permitirá el relevo de las decadentes élites por otras más voraces y depredadoras, más en contra de los objetivos nacionales y más supeditada a intereses imperiales, por más que se escondan en retóricas revolucionarias o de esa entelequia denominada 'Socialismo del siglo XXI'.

Además hay que resaltar, en esta parte, una experiencia histórica desechada por el régimen nacional populista, porque afecta su interés en continuar la 
centralidad del estatalismo: a fines de la década de los noventa en las áreas territoriales más deprimidas, como son las provincias centrales de la Sierra, se gestaron propuestas de regionalización territorial-horizontal, que teniendo en cuenta, por primera vez, la situación geo-política-estratégica vigente (unión de la Cuenca del Pacífico con el Océano Atlántico a través de la Amazonía, posicionamiento con China y los altos costos del canal de Panamá), se propuso la integración de los diversos pisos ecológicos y el aprovechamiento de las infraestructuras y equipamientos públicos existentes, a mejorarse o por construirse (puertos marítimos, sistemas viales y equipamientos de los centros poblados, entre otros) para impulsar sostenidamente el intercambio comercial y un encadenamiento productivo nacional y viable. Se lograron identificar parcialmente cuatro grupos "naturales" de provincias circunvecinas encadenadas (Zodenor: Esmeraldas, Carchi, Pichincha, Sucumbíos, Orellana e Imbabura; G-7: Tungurahua, Chimborazo, Cotopaxi, Bolívar, Pastaza, Morona Santiago y Manabí; Alianza Regional Sur: Guayas, Los Ríos, Azuay, Cañar y Morona Santiago; y, G-3: El Oro, Loja y Zamora Chinchipe), con participación activa y apoyo del sistema político seccional, sectores económicos y la sociedad civil local, que al constituirlos como tales podrían deparar para el país una gama de iniciativas y propuestas viables política, económica y socialmente en el contexto actual de globalización neoliberal, pero de construcción real y obligada de una ciudadanía como mecanismo alternativo para el desarrollo y el bienestar.

En esta perspectiva se debía apuntar a constituir a cada una de las regiones como sujetos económicos, sociales y políticos, recuperando una territorialidad que interactúe como parte de redes históricas aún vigentes (como lo plantearon J. P. Deler, Raymond Bromley, Cepeige, Nelson Gómez, José Rodríguez, entre otros). Lamentablemente, de lo reseñado nada se ha rescatado por parte de los 'iluminates' de la revolución ciudadana para introducirlo en el nuevo COOTAD, y más bien parece que las regiones propuestas son una forma de 'gatopardismo' burocrático para que se fortalezca un estatismo centralista.

No podemos concluir este artículo sin destacar los temas pendientes de una Agenda de los Gobiernos Autónomos Descentralizados para la actual coyuntura y para enfrentar las perversidades de la globalización, que nos están afectando ahora y lo harán en el futuro próximo. Las unidades territoriales como actores protagónicos de la mundialización exigen impulsar la competitividad 
frente al mercado global y su posicionamiento, según la función de cada una en la red urbana nacional y su ubicación en el territorio. Lo que se traduce en un fortalecimiento y especialización de su base económica, en un proyecto de incorporación de valor agregado y no de reprimarización. A lo que se agregan, un desarrollo urbano incluyente y equitativo intra e interurbano, la construcción de gobiernos locales que respondan a las demandas sociales de sus poblaciones; modalidades más accesibles y públicas de producción de los servicios urbanos; lucha integral y programada contra la pobreza; desaparición de la miseria, y protección del ambiente urbano, entre los más destacados.

La conjugación de todas estas políticas y programas mencionados y de una agenda para el desarrollo permitirá que se construya una sólida integración social nacional, el mejoramiento de la calidad de vida y bienestar para todos, que permitan disfrutar de una situación de desarrollo económico y humano sin exclusiones e inequidades sociales y fortaleciendo la ciudadanía y a la sociedad democrática en su conjunto.

Finalmente, las élites políticas locales han mutado en este último medio siglo en el país, pero parece que no lo suficiente para convertirse en verdaderos constructores de un nuevo destino histórico y para forjar un sólido sistema de partidos políticos que apunte a profundizar la democracia, auspiciar la participación de sus adherentes y servir de cadena de transmisión de las demandas sociales de sus poblaciones con el Estado, tanto a nivel nacional como seccional. Lamentablemente, a inicio del siglo XXI continúa en Ecuador el clientelismo, del 'tú me das tu voto, yo te doy una obra' de los caudillos-mesías locales, en cada una de las cuatro regiones geo-sociales y en el país en su conjunto, pero debido al estatalismo creciente se debilita la institucionalidad y merma la legitimidad de los gobiernos autónomos descentralizados. Por eso nosotros los ciudadanos conscientes y decididos a un Ecuador mejor, democrático, progresista y desarrollado, debemos recordar siempre lo que dijo Nicolás Maquiavelo:

En verdad, el único medio seguro de dominar una ciudad acostumbrada a vivir libre es destruirla. Quien se haga dueño de una ciudad así y no la aplaste, espere ser aplastado por ella. Sus rebeliones siempre tendrán por baluarte el nombre de la libertad y sus antiguos estatutos, cuyo hábito nunca podrá perder el tiempo ni los beneficios. Por mucho que se haga y 
se prevea, si los habitantes no se separan ni se dispersan, nadie se olvida de aquel nombre ni de aquellos estatutos, y a ellos inmediatamente recurren en cualquier contingencia (El Príncipe, Capítulo V).

\section{Bibliografía}

ACOSTA, Alberto, et al. (1996), Democracia, Desarrollo y Descentralización. Por una Propuesta Alternativa; Maestría de Desarrollo Regional, Facultad de Ciencias Económicas de la Universidad de Cuenca-ILDIS, Cuenca.

AYALA, Enrique (Editor) (1995), Nueva Historia del Ecuador, Quito: Corporación Editora Nacional, Vol. 11, 12, 13 y 14.

BAGÚ, Sergio (1979), Tiempo, Realidad Social y Conocimiento, México: Siglo XXI Editores, 6ta Edición.

BARRERA, Augusto (Coordinador), Ecuador: Un modelo para [Des]armar. Quito, Descentralización, Disparidades Regionales y Modo de Desarrollo, Grupo de Democracia y Desarrollo Local, diciembre de 1999.

CASTILlO, Bolívar (1997), Descentralización del Estado y Desarrollo Fronterizo, Quito: Impresión Gráficos Cobos, 2da edición.

Comisión para la Descentralización, Autonomías y Circunscripciones Territoriales- CONAM, Propuesta de Nuevo Modelo de Gestión para el Ecuador, CONAM-BEDE-GTZ, documento de trabajo, 2000.

CONAM-GTZ-CONCOPE-Gobierno de la Provincia del Pichincha, Consecuencias de la Transferencia de Competencias, Comisión Técnica de Descentralización, $\mathrm{s} /$ fecha, fotocopias.

CONAM, Descentralización y Autonomías, Memoria del Foro, Manta, abril 30-1 de mayo de 1999.

DONOSO, Patricio, Propuestas de Descentralización y Elementos de Análisis, Cordes-Konrad Adenauver Stiftung, No. 3, Quito, 2000.

ESPOL, Guayas Siglo XXI. Un Nuevo Desarrollo Regional con base en el Conocimiento, documento para el análisis interno, borrador, Guayaquil, 2000 . 
GUZMÁN, Marco, Realidad Nacional, Descentralización y Autonomías, Cordes-Konrad Adenauver Stiftung, No. 1, Quito, marzo de 2000.

HARDOY, Jorge y Morse, Richard (1998), Repensando la Ciudad de América Latina, Buenos Aires: GEL-IIED.

PETRAS, James (2001), Centralidad del Estado en el Mundo Contemporáneo, Argentina: Editorial Rebelión.

MARTÍNEZ, Esperanza (Editora) (2000), El Ecuador Post Petrolero, Acción Ecológica, Quito, junio de 2000, 1era edición.

MUÑOZ, Francisco (Compilador), Descentralización, Quito: Trama Social Editorial, Quito, 1999.

OJEDA, Lautaro (1998), Encrucijadas y Perspectivas de la Descentralización en el Ecuador, Quito: Abya-Yala.

PGU-PNUD-UNCHS-Banco Mundial-GTZ, ¿Descentralizar en América Latina?, Quito: Vol. No. 3, 1995.

Publicaciones de Diálogo 21, PNUD, Guayaquil.

QUINTERO, Rafael y Erika Silva (1991), Ecuador: Una Nación en Ciernes, Quito: Abya-Ayala, X 3 Tomos.

QUNTERO, Rafael (2000), Ponencia de Discusión, ILDIS, Guayaquil, 18 de abril, 2001.

RODRÍGUEZ, Carlos (Director), Descentralización. Desde la Diversidad del Pensamiento, Facultad de Ciencias Administrativas de la Universidad Central del Ecuador, Quito: Editorial Universitaria.

Secretaría Técnica del Frente Social (STFS), Pobreza y Capital Humano en el Ecuador, Quito, 1997.

Envío 4 de octubre /2010 - aceptación 5 de noviembre /2010 